\title{
Erratum
}

\section{Changes in Regional and Overall Lung Function After Bronchography*}

\author{
M. Richez, P. Ravez, G. Godart, J.L. Halloy, and Y. Robience
}

Hôpital de Warquignies, Service de Pneumologie, Boussu, Belgium

Eur. J. Nucl. Med. 5, 447-480 (1980)

On pp 479, 480 the paragraphs appeared in the wrong order.

The last two paragraphs on $\mathrm{p} 480$ beginning with "Although the third hypothesis is the most likely ..." should be inserted on $\mathrm{p} 479$, second column, before the paragraph beginning. with "A second explanation may be that ....". 